\title{
INDICADORES PER Y FPEIR PARA EL ANÁLISIS DE LA SUSTENTABILIDAD EN EL MUNICIPIO DE CIHUATLÁN, JALISCO, MÉXICO ${ }^{1}$
}

\author{
PSR AND DPSIR INDICATORS FOR ANALYSIS \\ OF SUSTAINABILITY IN THE MUNICIPALITY \\ OF CIHUATLÁN, JALISCO, MEXICO
}

Roberto Armando Vázquez-Valencia², Rosa M. García-Almada ${ }^{3}$

Fecha de recepción: 10 de septiembre del 2017

Fecha de aceptación: 18 de diciembre del 2017

1- Se agradecen los comentarios de dos dictaminadores anónimos que permitieron mejorar sustancialmente este trabajo.

2- Nacionalidad: Mexicana, Grado: Doctor. Especialización: Gobierno y administración pública. Adscripción: Consultor privado. Correo electrónico: armandvaz@gmail.com. (D) ORCID: https://orcid.org/0000-0003-1532-035X

3- Nacionalidad: Mexicana. Grado: Doctorado. Especialización: Estudios regionales. Adscripción: Universidad Autónoma de Ciudad Juárez. (D) ORCID: https://orcid.org/0000-0003-2330-8385 


\section{Resumen:}

Este artículo tiene como objetivo analizar el desarrollo sostenible del municipio de Cihuatlán en la región Costa Sur del estado de Jalisco (México) mediante indicadores Presión-Estado-Respuesta (PER) y Fuerzas conductoras-PresiónEstado-Impacto-Respuesta (FPEIR). El trabajo se realizó enfatizando tres sectores: forestal, agropecuario y turístico. La información fue obtenida de documentos oficiales, participación en talleres y entrevistas a actores relevantes, estos últimos ayudaron a identificar los problemas ambientales y realizaron una valoración subjetiva de su estado. Se identificó como principal problema el manejo inadecuado de los residuos, otras presiones están relacionadas con la degradación de los ecosistemas y la biodiversidad, vulnerabilidad ante el cambio climático y contaminación del aire. En lo que refiere a respuestas, destacó la deficiente aplicación de las leyes existentes sobre gestión ambiental, así como la escasa importancia que tiene la protección y respeto del ambiente, particularmente entre funcionarios públicos locales. La originalidad radica en la propuesta de un conjunto de indicadores municipales que deben cuantificarse para conocer la forma de alcanzar un desarrollo sostenible.

Palabras clave: Desarrollo local, indicadores de sostenibilidad, gestión ambiental, Jalisco, México.

\section{Abstract:}

This article aims to analyze the sustainable development of the municipality of Cihuatlan in the South Coast region of the state of Jalisco (Mexico) using Pressure-State-Response (PSR) and Driving Forces-Pressure-State-ImpactResponse (DPSIR) indicators. The work was done emphasized three sectors: forestry, agriculture and tourism. The information was obtained from official documents, participation in workshops and interviews with relevant actors, the latter helped to identify environmental problems and made a subjective assessment of their status. The main problem identified was inadequate waste management, other pressures are related to ecosystem degradation and biodiversity, vulnerability to climate change and air pollution. Regarding responses, highlighted the poor application of existing laws on environmental management, as well as the low importance of protection and respect for the environment, particularly among local public officials. The originality lies in the proposal of a set of municipal indicators that must be quantified in order to know how to achieve sustainable development.

Keywords: Local development, sustainability indicators, environmental management, Jalisco, Mexico. 


\section{Introducción}

$\mathrm{E}$ 1 crecimiento poblacional mundial de las últimas décadas en zonas urbanas y rurales ha tenido repercusiones negativas en el entorno, destaca particularmente el agotamiento de los recursos naturales de los que depende directamente la humanidad, por lo que se vuelve necesario abordar los diferentes aspectos de este crecimiento, así como los relacionados con el aprovechamiento y gestión de los recursos, partiendo de un enfoque holístico que integre la mayoría de factores que lo influyen -sean físicos, legales, sociales o políticos.

En este contexto, a partir de la segunda mitad de la década de los noventa, al menos en México, las políticas de planeación regional han vuelto a la escena, sobre todo en el estado de Jalisco, como iniciativas que han venido ganando terreno en temas como el aprovechamiento de los recursos naturales y humanos en la búsqueda de un desarrollo equilibrado y sostenible.

Atendiendo a lo anterior, este artículo se enfoca en analizar el desarrollo sostenible del municipio de Cihuatlán, ubicado en la región Costa Sur del estado de Jalisco (México) usando indicadores PresiónEstado-Respuesta (PER) y Fuerzas conductoras-Presión-Estado-Impacto-Respuesta (FPEIR). Con la meta de proponer un conjunto de indicadores que puedan ser cuantificados de forma sistemática por las autoridades para conocer el estado y las respuestas de cara a la sostenibilidad ambiental.

La investigación presentada sugiere la necesidad de una gestión ambiental adecuada a las necesidades regionales con el objetivo de conservar y disminuir el impacto en los ecosistemas existentes debido a las actividades forestales, agropecuarias y turísticas que por vocación están presentes. Se plantea la necesidad de una adecuada visión de desarrollo equilibrado y sostenible para la conformación de una zona competitiva en términos de desarrollo y al mismo tiempo de conservación de los recursos naturales con un diseño de políticas públicas adecuadas que se fundamenten en nuevas formas de gestión coordinadas y de cooperación entre los agentes locales.

El supuesto asumido en este trabajo es que en la medida en que exista mayor relación, organización y cooperación entre agentes, éstos podrán enfrentarse a los cambios de su entorno global y local, proponiendo mejores alternativas y soluciones a sus problemas de sostenibilidad. Tras comentar el planteamiento de la investigación, queda indicar que el reporte se organizó de la siguiente forma: en la primera parte se presenta una breve revisión de la literatura respecto al papel que juegan los indicadores PER y FPEIR en los estudios de desarrollo sostenible; en la segunda se explica la metodología utilizada; en la tercera se contextualiza a la región y exponen los resultados; finalmente, se concluye sintetizando los hallazgos y remarcando la originalidad del trabajo.

\section{Revisión de la literatura}

En la investigación se parte de la siguiente definición de desarrollo sostenible (Brundtland, 1987): “... desarrollo que satisface las necesidades del presente sin comprometer la habilidad de las futuras generaciones para satisfacer sus propias necesidades." De acuerdo con Glavic y Lukman (2007:1884), el desarrollo sustentable enfatiza la evolución humana desde un punto de vista de responsabilidad económica 
que es acorde con los procesos naturales y del entorno. Por lo que las dimensiones políticas son centrales. Bajo un paradigma de desarrollo sostenible las limitaciones de recursos económicos, sociales y naturales son consideradas de tal forma que contribuyan al bienestar presente y de las futuras generaciones y puede aplicarse en los ámbitos local, regional, nacional e internacional, basado en la voluntad política. (Para mayores referencias véase Eizenberg y Jabareen, 2017 y Orenstein y Shach-Pinsley, 2017).

Conectado con lo mencionado, los indicadores se entienden como un sistema de señales que facilitan la evaluación y el progreso de un país o una región. Estos son herramientas que coadyuvan al trabajo de diseño y evaluación de las políticas públicas. Con esta herramienta, se fortalecen y sustentan las decisiones de manera informada para impulsar el desarrollo en una determinada región.

La Organización para la Cooperación y Desarrollo Económico (OCDE, 1993) considera que un indicador es un parámetro o un valor derivado de otros parámetros, dirigido a proveer información y descripción del estado de un fenómeno. Pero dicha descripción con un significado añadido aún mayor que el directamente asociado a su propio valor (ver también Ott, 1978; Chevalier et al., 1992; Gallopín, 1996; Pannel y Schilizzi, 1999).

Según Guttman et al. (2004), los indicadores toman sentido al considerarlos como un sistema, como construcciones ordenadas y coherentes. Cualquier sistema de indicadores busca de alguna forma organizar la información disponible para proporcionar claridad en un asunto en específico o un problema planteado en la sociedad. Por lo que un sistema de indicadores no debe limitarse al reduccionismo de únicamente recopilar un conjunto de series, sino intentar encontrar las relaciones entre dichas series. De igual forma, los resultados de un sistema de indicadores deben siempre acompañarse de un texto de interpretación que explique lo que las cifras o los elementos cualitativos considerados muestran de acuerdo con el marco de referencia preestablecido.

Fraser et al. (2006), presentan una serie de conclusiones primarias en su estudio sobre la importancia de los procesos participativos para la identificación de indicadores de sostenibilidad donde destacan que la identificación y selección de indicadores de sostenibilidad no provee únicamente bases de datos evaluativas para llevar a cabo decisiones de gestión, sino que va más allá; es decir, que es, o debiera ser, un proceso de implicación de la población que coadyuve a la selección de indicadores a la vez que ofrece una oportunidad para proporcionar una especie de poder e involucramiento de la comunidad que las distintas aproximaciones tradicionales no han conseguido.

En el presente artículo se comparte esta visión sobre la importancia que tiene la inclusión de la población (actores) en los foros de toma de decisiones y en la evaluación-análisis de los problemas de gestión para la generación de indicadores. Ya que de no hacerlo se corre el riesgo de que algunos problemas o indicadores sean vistos como irrelevantes por los actores principales y por los responsables de las políticas públicas (para más información sobre indicadores de desarrollo sostenible ver Arias, 2006).

Recientemente, la mayoría de los países están utilizando indicadores de desarrollo sostenible, la mayoría de ellos fundamentados en el marco ordenador PER desarrollado por la OCDE (1993) a partir del trabajo de Rapport y Friend (1979) (ver para el caso chino Sun et al., 2016). El esquema PER está basado en una lógica de causalidad; es decir, las actividades humanas ejercen presiones sobre el ambiente y cambian la calidad y cantidad de los recursos naturales (estado). Asimismo, la sociedad responde a estos cambios a través de políticas ambientales, económicas y sectoriales (respuestas). 


\section{Enfoque Presión- Estado- Respuesta}

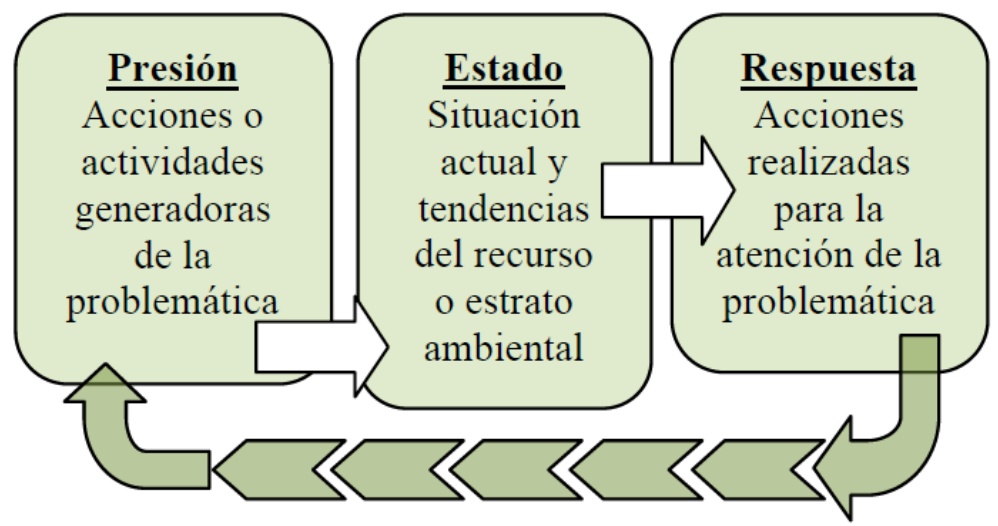

Fuente: Elaboración propia con base en OCDE (1998).

La lógica del PER es en extremo sencilla, pero de gran utilidad para el análisis de los vínculos que existen entre las condiciones ambientales y las actividades humanas (sobre su uso para la evaluación del impacto acumulado ver Neri et al., 2016). El esquema responde a tres preguntas básicas: la primera; ¿qué está ocurriendo con el ambiente? (estado), segunda, ¿por qué está ocurriendo? (presión), tercera, ¿qué se está haciendo al respecto? (respuesta). Por lo que los indicadores representan un valioso instrumento para cuantificar, simplificar y sistematizar la información relacionada con los distintos aspectos del ambiente y la interacción humana. A partir del marco PER, la Agencia de Medio Ambiente Europea creó un modelo analítico que denominó FPEIR (Fuerzas conductoras-Presión-Estado-Impacto-Respuesta) (European Environment Agency, 1999) (ver una aplicación a Palestina en Mogheir y Lubbad, 2008 y Pires et al., 2016 para una aplicación a la gestión del agua). En conjunto PER y FPEIR son de utilidad en el análisis de los elementos interactuantes a nivel local en la gestión ambiental para la promoción del desarrollo sostenible tal y como se muestra en la sección de resultados.

\subsection{México: Indicadores de desarrollo sostenible}

La génesis sobre indicadores de sostenibilidad para el caso de México puede ubicarse en 1994 con la creación de la Secretaría de Medio Ambiente, Recursos Naturales y Pesca, quien en colaboración con el Instituto Nacional de Ecología (INE), órgano desconcentrado de la misma Secretaría, han trabajado la línea ambiental y del desarrollo sostenible. Dichas instituciones elaboraron trabajos bajo el esquema PER de la OCDE, enfocados a la evaluación del desempeño de la política ambiental.

Aunado a lo anterior, México participó en la prueba piloto de la Comisión de Desarrollo Sostenible (CDS) de la ONU iniciada en 1997 donde logró elaborar 113 de los 134 indicadores propuestos en la CDS. De los cuales 39 se clasificaron en el marco PER como de presión, 43 de estado y 31 de respuesta. 
Del total, 97 fueron elaborados de acuerdo con las hojas metodológicas propuestas por la CDS, y otros 16 fueron de carácter alternativo.

Por otra parte, el Instituto Nacional de Estadística y Geografía (INEGI) en colaboración con el INE publicaron en julio de 2007 una selección de los indicadores de desarrollo sostenible de México, con el objetivo de proporcionar un conjunto de indicadores que contribuyeran al diseño de estrategias y políticas en materia ambiental. La generación de estos indicadores se ha convertido en una prioridad para México, ya que desde entonces se integra información vinculante de los temas económico, demográfico, ambiental e institucional (Quiroga, 2007).

De forma reciente (2014), en cumplimiento con la Agenda 2030 para el desarrollo sostenible, México a través del INEGI creó el Sistema de Información de los Objetivos de Desarrollo Sostenible (SIODS) el cual contiene información a nivel nacional y por entidad federativa de las siguientes dimensiones: fin de la pobreza; hambre cero; salud y bienestar; educación de calidad; igualdad de género; agua limpia y saneamiento; energía asequible y no contaminante; trabajo decente y crecimiento económico; industria, innovación e infraestructura; reducción de las desigualdades; ciudades y comunidades sustentables; producción y consumo responsables; acción por el clima; vida submarina; vida de ecosistemas terrestres; paz, justicia e instituciones sólidas y alianzas para lograr objetivos.

Por otra parte, al buscar trabajos publicados en revistas científicas que hayan utilizado los indicadores PER y FPEIR para el caso mexicano en el contexto del desarrollo sostenible local, no se encontró alguno, al menos en Scholar Google, Web of Science y Redalyc. En esta última base destaca el trabajo de Chirino et al. (2008), quienes estudiaron la Comarca Marina Baixa en España, encontraron “... un déficit hídrico anual, elevado crecimiento urbanístico y turístico, y alta densidad demográfica en el litoral y zona intermedia; que unido al crecimiento de la agricultura intensiva de regadío genera un balance hídrico negativo a escala de unidades ambientales" (Chirino et al., 2008:107). Los autores concluyen que el modelo de desarrollo de la comarca es ecológicamente insostenible.

Entre las críticas que se pueden hacer a este estudio es que es no identifica con claridad los actores clave en diferentes niveles geográficos y que descuida el rol de la gestión pública al centrarse en aspectos estrictamente ambientales. Tras revisar la literatura, en lo que sigue, se presenta el procedimiento utilizado en la investigación y los resultados, lo que se espera, permita al lector destacar la originalidad del trabajo, pero particularmente su importancia en términos de política pública para el desarrollo sostenible en un municipio de México.

\section{Metodología de investigación}

La investigación se realizó en seis etapas. La primera consistió en la búsqueda de información documental (revisión bibliográfica) para establecer el concepto de sostenibilidad que guiaría las reflexiones y observaciones realizadas durante el trabajo de campo, así como ubicar otras investigaciones relacionadas y leer proyectos y documentos de gobierno relacionados con el tema.

En la segunda se revisaron estudios específicos sobre los diversos indicadores para la sostenibilidad, encontrándose que las estrategias PER y FPEIR resultaban pertinentes y actualizadas. La tercera implicó asistir a tres talleres organizados por las autoridades del gobierno municipal y estatal en los cuáles se 
trabajaron los siguientes temas con un grupo de actores relevantes: 1) proyectos de sostenibilidad; 2) problemas ambientales municipales y 3 ) retos ambientales de la actividad económica. Con el conocimiento del municipio y la asistencia a talleres, así como el procedimiento indicado abajo, fue posible en una cuarta etapa identificar actores clave.

En la quinta etapa se entrevistó a tres actores relevantes del ámbito gubernamental que proporcionaron información sobre los demás y las cinco dimensiones de sostenibilidad indicadas líneas abajo, los entrevistados fueron: 1) director de ecología municipal; 2) director de promoción económica y 3) directora de turismo. Por razones financieras no fue posible ampliar la muestra de personas entrevistadas.

Aclarar que el trabajo de campo se realizó de forma no continua entre marzo del 2015 y abril del 2016. Finalmente, en la sexta etapa se sistematizó la información recabada con base en los datos obtenidos de los informantes, talleres y la experiencia tras recorrer el municipio y observar la dimensión de los diferentes problemas de sostenibilidad. Todo al final se resumió en los indicadores PER y FPEIR. Señalar que, debido a las dificultades para encontrar información cuantitativa de los diferentes problemas, se procedió a utilizar referencias cualitativas a los mismos, esperando que el resultado sirva para que las autoridades se den a la tarea de crear iniciativas para capturar la información estadística necesaria con fines de seguimiento, evaluación y por supuesto corrección.

\section{Figura 2. Proceso metodológico para el estudio de caso}

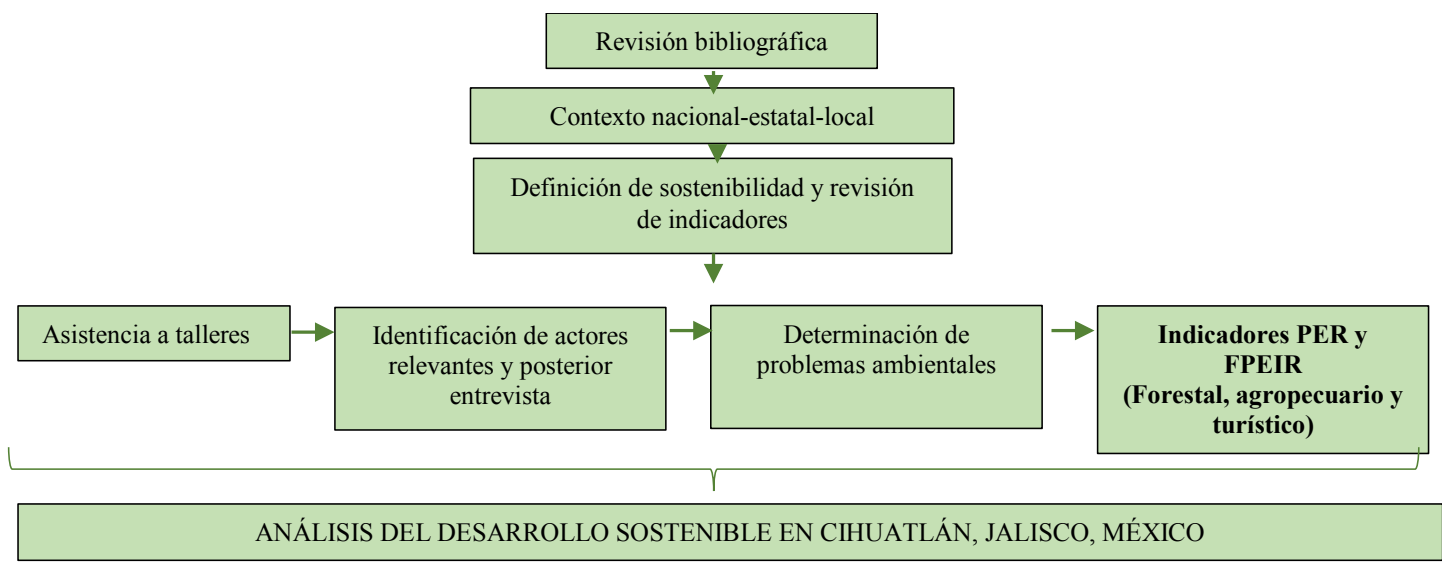

Fuente: Elaboración propia.

En lo que refiere a los actores clave se recurrió a la "Guía para la Identificación de Actores Clave" de la Comisión Nacional del Agua (CONAGUA), documento publicado por la Secretaría de Medio Ambiente y Recursos Naturales (SEMARNAT). En esta guía se mencionan los siguientes criterios que permiten identificar actores clave: 1) Forman parte de la sociedad asentada en el área de implantación del proyecto o campo de acción; 2) los cuales representan intereses legítimos del grupo; 3) cuentan con funciones y atribuciones en relación directa con los objetivos que se han planteado; 4) disponen de habilidades y capacidades, así como conocimiento, infraestructura y recursos para proponer, atender y solventar problemas científico-técnicos; 5) cuentan con recursos financieros (donación de recursos) o mecanismos de financiamiento; 6) tienen capacidad de gestión y negociación con los diversos agentes y/o con los diversos niveles gubernamentales que permiten construir consensos y acuerdos. 
Una vez identificados los actores, las dimensiones de sostenibilidad consideradas fueron cinco: 1) política; 2) ecológica; 3) epistemológica y científica; 4) económica y 5) cultural (de acuerdo con SEMARNAT, 2006). Debido a su importancia para la economía y sociedad locales, así como por razones presupuestarias y de tiempo, se decidió concentrar el análisis del desarrollo sostenible en tres sectores: forestal, agropecuario y turístico.

\section{Resultados de investigación}

Este apartado presenta los resultados de investigación, además ubica geográfica y contextualmente el estado de Jalisco y la correspondiente región de estudio. Para después señalar actores con mayor influencia en la conformación o promoción del desarrollo sostenible, a lo que sigue una presentación de los problemas ambientales detectados. De forma central, se exponen los indicadores cualitativos PER y FPEIR con énfasis en tres sectores de relevancia para el municipio: forestal, agropecuario y turístico.

\subsection{Jalisco, Costa Sur y Cihuatlán}

El estado de Jalisco se localiza en la región Centro-Occidente de México. En esta entidad federativa se concentra la mayor actividad industrial, comercial y de servicios del país, ya que Guadalajara, su capital, es la tercera zona metropolitana de mayor importancia nacional. Aunado a su ubicación geográfica estratégica que le permite conectar el centro con el norte tanto por medios terrestres, como aéreos y marítimos. De acuerdo con el último censo del 2010, la entidad tenía una extensión territorial de 78,588 km², lo que representaba el 4 por ciento de la nación. Su población era de 7,350,682 habitantes, distribuida en 124 municipios. La mayor parte de su población es urbana, 87 por ciento.

El estado ocupaba la cuarta posición en términos económicos a nivel nacional, al aportar 6.6 por ciento del PIB en 2010, destacando como líder en el PIB agropecuario con 11.7 por ciento. Aunque la principal actividad económica son las industrias manufactureras con el 42 por ciento del total estatal, destacan la industria electrónica, de tecnologías de información, alimentos, bebidas y tabaco; así como los sectores joyero, textilero y calzado. La zona metropolitana de Guadalajara junto a Puerto Vallarta y la región Costa Sur es la de mayor afluencia turística lo que fortalece al sector servicios contribuyendo al desarrollo de la entidad (Escalera, 2013).

El estado de Jalisco se encuentra dividido en doce regiones administrativas (entre paréntesis el número de municipios): 1) Norte (10); 2) Altos Norte (8); 3) Altos Sur (12); 4) Ciénega (9); 5) Sureste (10); 6$)$ Sur (12); 7) Sierra de Amula (14); 8) Costa Sur (6); 9) Costa-Sierra Occidental (8); 10) Lagunas (12); 11) Valles (12) y 12) Centro (12). 
Figura 3. Región Costa Sur de Jalisco y municipio de Cihuatlán

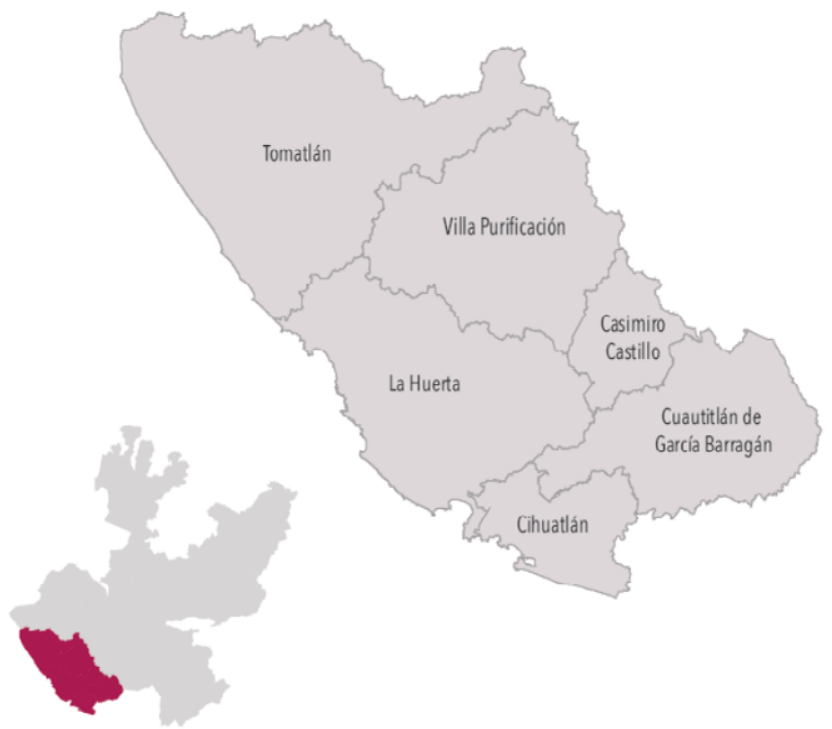

Fuente: Instituto de Información Estadística y Geográfica del Estado de Jalisco (IIEG).

La región Costa Sur tiene una superficie total de $7,004.39 \mathrm{~km}^{2}$, que equivalen al 8.74 por ciento de la superficie estatal, alberga una población de 149,967 habitantes (INEGI, 2010), lo que representa 2.22 por ciento de la población total del estado. Está compuesta por seis municipios: Cihuatlán, Casimiro del Castillo, Tomatlán, Cuautitlán, La Huerta y Villa Purificación. Su espacio geofísico se localiza limitando al norte y noroeste con los municipios jaliscienses de la región Costa-Sierra. Al este con el estado de Colima; al sur y suroeste con el Océano Pacífico y al noreste con municipios de las regiones Sierra de Amula y Sur. La región cuenta con bastos recursos naturales tanto en playa como en espacios tierra adentro, además de atractivos culturales y deportivos, la Reserva de la Biosfera Sierra de Manantlán y una base consolidada de servicios turísticos (PED 2030, 2007).

La población en Cihuatlán era de 41 mil 300 personas (INEGI, 2015), donde el 50.1 por ciento eran hombres y el resto mujeres, por su tamaño, el municipio se clasifica como ciudad media. Del total de la Costa Sur, el municipio concentraba el 27.2\% de la población. Las estimaciones para 2020 indican que la población aumentará a 48 mil 184 habitantes, donde aproximadamente 24 mil 259 personas serán hombres y 23 mil 925 mujeres. En el municipio, la cabecera municipal es Cihuatlán, localidad más poblada con 18 mil 164 personas (46.6\% del total), le sigue San Patricio (19.4\%), Barra de Navidad (11.1\%), Jaluco (8.1\%) y Emiliano Zapata (4.7\%).

En lo económico, las actividades que predominan son las comerciales y de servicios, así como las vinculadas a las actividades agropecuarias, la industria manufacturera tiene una participación despreciable. En 2014 de 2,513 unidades económicas, 54 por ciento, correspondían a servicios, 39.4 por ciento comercio, 6.1 por ciento industria y el resto agricultura. De acuerdo con IIEG (2016), el municipio en 2015 tenía un grado de marginación bajo a nivel estatal, aunque con un 44.8 por ciento de su población en situación de pobreza moderada y 10.9 por ciento en pobreza extrema (para una contextualización amplia de Cihuatlán revise IIEG, 2016). 


\subsection{Identificación de actores clave, problemas ambientales y modelo PER-FPEIR}

En lo que sigue se enumeran los actores clave identificados en la región. La investigación, como se mencionó antes, se enfocó en los sectores: forestal, agropecuario y turístico. En la parte agrícola los actores identificados fueron: Asociación Ganadera Local del municipio de Cihuatlán; Unión de Ejidos Luís Echeverría; Asociación Agrícola Local de Productores de Plátano del Valle de Cihuatlán; Asociación Agrícola Local de Productores de Coco del Valle de Cihuatlán; Asociación Agrícola Local de Productores de Mango de Jaluc; El Coco Loco. Agro negocios; Empresa Javier Ashida; S.C. Deshidratadora de Fruta El Aguacate y Empacadoras en Jaluco. En acuacultura y pesca: S.C. Agroacuícola Temacapulin de R.L.; S.C.P.P. Ribera de Melaque; S.C. Ostioneros y Pescadores de Barra de Navidad; S.C.P.P. Pescadores y Buzos del Pacífico; Grupo Drawast S.C. de R.L. de C.V.; S.C.P.P. Ribera de Melaque S.C. de R.L.; S.C. «Rancho Viejo» de R.L.; S.C. "Punta Conchero" de R.L. y S.C. Puerto Viejo de la Navidad de R.L. En lo forestal: Ejido Lázaro Cárdenas Cihuatlán; Asociación de Silvicultores del Sur-Sureste del Estado de Jalisco A.C.; Comunidad Indígena de Cihuatlán; Ejido Las Guasimas y "Madera de Palma, S.A. de C.V." (Madepal). En conservación: Universidad de Guadalajara; Universidad Autónoma de Guadalajara; CIDECOS A.C.; PROLATULE A.C. y ECOBANA, A.C. En turismo: Asociación de Hoteles y Moteles en la Costa Sur de Jalisco; Asociación de Restauranteros de la Costa Alegre; Cooperativa de Servicios Turísticos de Barra de Navidad y Cooperativa de Servicios Turísticos de Miguel López de Legazpi.

\section{Cuadro 1. Actores responsables de la gestión por sector en Cihuatlán}

\begin{tabular}{|c|c|c|c|}
\hline $\begin{array}{l}\text { Recurso/sector } \\
\text { productivo }\end{array}$ & Aspectos & Actor responsable & Nivel de gobierno \\
\hline Agua & Distribución y calidad & $\begin{array}{c}\text { Comisión Nacional del Agua, } \\
\text { organismos municipales, } \\
\text { usuarios }\end{array}$ & $\begin{array}{l}\text { Federal, estatal y } \\
\text { municipal }\end{array}$ \\
\hline Suelo & $\begin{array}{l}\text { Aprovechamiento y } \\
\text { restauración }\end{array}$ & $\begin{array}{l}\text { Agricultores, distritos de } \\
\text { riego, unidades de riego } \\
\text { (propietarios, ejidatarios y } \\
\text { comuneros) }\end{array}$ & $\begin{array}{l}\text { Decisiones orientadas } \\
\text { por incentivos de políti- } \\
\text { cas sectoriales federales } \\
\text { y estatales }\end{array}$ \\
\hline Biodiversidad & $\begin{array}{l}\text { Aprovechamiento, } \\
\text { restauración y conser- } \\
\text { vación }\end{array}$ & $\begin{array}{l}\text { Comisión Nacional de Áreas } \\
\text { Naturales Protegidas, planta- } \\
\text { ciones, (propietarios públicos } \\
\text { y privados, ejidatarios y } \\
\text { comuneros) }\end{array}$ & $\begin{array}{l}\text { Decisiones orientadas } \\
\text { por incentivos de políti- } \\
\text { cas sectoriales federales } \\
\text { y estatales }\end{array}$ \\
\hline Urbano & $\begin{array}{l}\text { Desarrollo urbano e } \\
\text { impacto ambiental, } \\
\text { zonificación y reservas }\end{array}$ & Municipio & Estatal y municipal \\
\hline
\end{tabular}


- Revista de Ciencias Sociales y Humanidades. ISSN-P: 0188-9834 ISSN-E: 2395-8669.

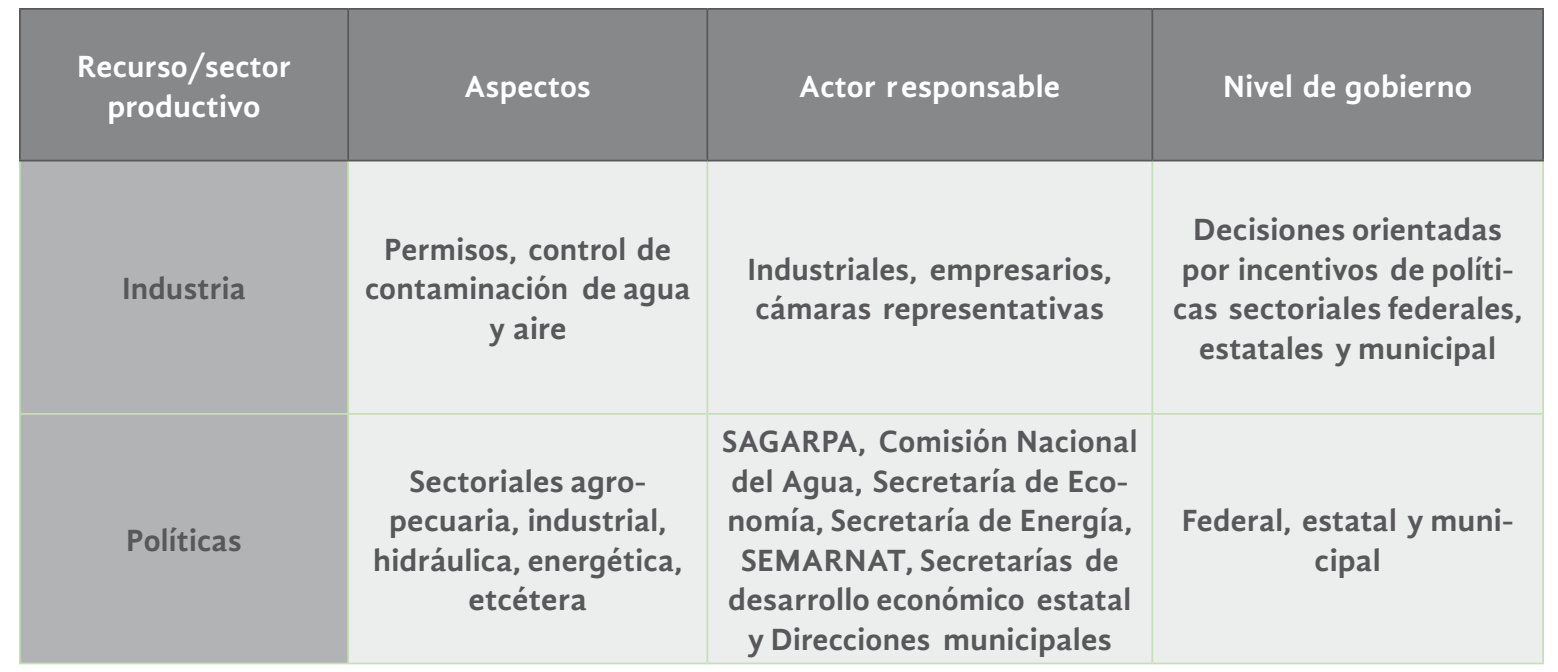

Fuente: Elaboración propia con base en Caire (2007:197).

El Cuadro 1 muestra los aspectos vinculantes y de gestión que requiere una planeación y óptimo manejo de los recursos naturales. Revela los consensos necesarios para que los planes o programas de mejora del ambiente aplicados por las administraciones locales sean exitosos. Ya que los agentes locales son los que están mejor informados sobre los problemas reales y potenciales en cada región, más que las agencias estatales o federales.

Cuadro 2. Actores clave de acuerdo con proyectos estratégicos municipales

\begin{tabular}{|c|c|c|c|c|c|}
\hline \multirow[b]{2}{*}{$\begin{array}{l}\text { PROYECTO } \\
\text { ESTRATEGICO }\end{array}$} & \multirow[b]{2}{*}{$\begin{array}{l}\text { COMUNIDAD/ } \\
\text { LOCALIDAD }\end{array}$} & \multicolumn{3}{|c|}{ INVOLUCRADOS DEL SECTOR } & \multirow[b]{2}{*}{$\begin{array}{c}\text { SECTOR SOCIAL } \\
\text { O PRIVADO }\end{array}$} \\
\hline & & $\begin{array}{c}\text { DEPENDENCIAS } \\
\text { MUNICIPALES O } \\
\text { REGIONALES }\end{array}$ & $\begin{array}{l}\text { DEPENDEN- } \\
\text { CIAS ESTAT } \\
\text { ALES }\end{array}$ & $\begin{array}{l}\text { SECRETARIAS } \\
\text { FEDERALES }\end{array}$ & \\
\hline $\begin{array}{l}\text { Conservación de los } \\
\text { recursos naturales } \\
\text { del municipio }\end{array}$ & $\begin{array}{l}\text { Ejidos, comunida- } \\
\text { des, cooperativas, } \\
\text { productores, } \\
\text { prestadores de } \\
\text { servicios turís- } \\
\text { ticos }\end{array}$ & $\begin{array}{c}\text { Dirección muni- } \\
\text { cipal de Ecología } \\
\text { y Turismo. } \\
\text { Centro de Apoyo } \\
\text { al Desarrollo } \\
\text { Rural (CADER) }\end{array}$ & $\begin{array}{c}\text { SEMADET } \\
\text { Secretaría de } \\
\text { Desarrollo } \\
\text { Rural (SEDER) } \\
\text { y Secretaría } \\
\text { de Desarrollo } \\
\text { Urbano (SE- } \\
\text { DEUR) }\end{array}$ & $\begin{array}{l}\text { SEMARNAT } \\
\text { SAGARPA SCT } \\
\text { SEMARINA }\end{array}$ & $\begin{array}{c}\text { Grupo Ecológico } \\
\text { Bahía de la Navi- } \\
\text { dad (ECOBANA, } \\
\text { AC) } \\
\text { Universidad de } \\
\text { Guadalajara }\end{array}$ \\
\hline $\begin{array}{c}\text { Programa de } \\
\text { conservación y ma- } \\
\text { nejo de los recursos } \\
\text { forestales }\end{array}$ & $\begin{array}{c}\text { Ejidos, Comuni- } \\
\text { dades }\end{array}$ & CMDRS & SEDER & CONAFOR & $\begin{array}{c}\text { Consultoresex- } \\
\text { ternos }\end{array}$ \\
\hline
\end{tabular}




\begin{tabular}{|c|c|c|c|c|c|}
\hline \multirow[b]{2}{*}{$\begin{array}{l}\text { PROYECTO } \\
\text { ESTRATEGICO }\end{array}$} & \multirow[b]{2}{*}{$\begin{array}{l}\text { COMUNIDAD/ } \\
\text { LOCALIDAD }\end{array}$} & \multicolumn{3}{|c|}{ INVOLUCRADOS DEL SECTOR } & \multirow[b]{2}{*}{$\begin{array}{c}\text { SECTOR SOCIAL } \\
\text { O PRIVADO }\end{array}$} \\
\hline & & $\begin{array}{c}\text { DEPENDENCIAS } \\
\text { MUNICIPALES O } \\
\text { REGIONALES }\end{array}$ & $\begin{array}{l}\text { DEPENDEN- } \\
\text { CIAS ESTAT } \\
\text { ALES }\end{array}$ & $\begin{array}{c}\text { SECRETARIAS } \\
\text { FEDERALES }\end{array}$ & \\
\hline $\begin{array}{c}\text { Proyecto de reha- } \\
\text { bilitación de micro- } \\
\text { cuencas y cuerpos } \\
\text { de agua }\end{array}$ & $\begin{array}{l}\text { Ejidos, comunida- } \\
\text { des, cooperativas, } \\
\text { productores, } \\
\text { prestadores de } \\
\text { servicios turís- } \\
\text { ticos }\end{array}$ & $\begin{array}{c}\text { Dir. municipal de } \\
\text { Ecología y direc- } \\
\text { ción de Turismo. } \\
\text { CADER, } \\
\text { CMDRS }\end{array}$ & $\begin{array}{c}\text { SEMADET, SE- } \\
\text { DER, SEDEUR, } \\
\text { CEAS }\end{array}$ & $\begin{array}{l}\text { SEMARNAT, } \\
\text { SAGARPA, SCT, } \\
\text { SEMARINA, } \\
\text { FIRCO }\end{array}$ & $\begin{array}{c}\text { ECOBANA, } \\
\text { Centro Universi- } \\
\text { tario de la Costa } \\
\text { Sur CUCSUR } \\
\text { (Universidad de } \\
\text { Guadalajara) }\end{array}$ \\
\hline $\begin{array}{l}\text { Proyecto de in- } \\
\text { fraestructura para } \\
\text { tratamiento de } \\
\text { aguas negras }\end{array}$ & $\begin{array}{l}\text { Ejidos, comunida- } \\
\text { des, cooperativas, } \\
\text { productores, } \\
\text { prestadores de } \\
\text { servicios turís- } \\
\text { ticos }\end{array}$ & $\begin{array}{c}\text { Dir. municipal de } \\
\text { Ecología y direc- } \\
\text { ción de Turismo. } \\
\text { CADER, } \\
\text { CMDRS }\end{array}$ & $\begin{array}{l}\text { SEMADET SE- } \\
\text { DER, SEDEUR, } \\
\text { CEAS }\end{array}$ & $\begin{array}{l}\text { SEMARNAT, } \\
\text { SAGARPA, } \\
\text { Comisión } \\
\text { Nacional del } \\
\text { Agua }\end{array}$ & $\begin{array}{c}\text { ECOBANA, CUC- } \\
\text { SUR APROSA- } \\
\text { NIDAD Melaque } \\
\text { AC. }\end{array}$ \\
\hline $\begin{array}{l}\text { Creación de uni- } \\
\text { dades de manejo } \\
\text { ambiental }\end{array}$ & $\begin{array}{c}\text { Ejidos, comunida- } \\
\text { des, cooperativas, } \\
\text { productores, } \\
\text { prestadores de } \\
\text { servicios turís- } \\
\text { ticos }\end{array}$ & $\begin{array}{l}\text { Dir. municipal } \\
\text { de Ecología y } \\
\text { dirección de } \\
\text { Turismo. } \\
\text { CMDRS }\end{array}$ & $\begin{array}{l}\text { SEMADET SE- } \\
\text { DER, SEDEUR. }\end{array}$ & $\begin{array}{l}\text { SEMARNAT, } \\
\text { SAGARPA, } \\
\text { CONAFOR }\end{array}$ & $\begin{array}{c}\text { ECOBANA AC, } \\
\text { CUCSUR APRO- } \\
\text { SANIDAD } \\
\text { MELAQUE, }\end{array}$ \\
\hline $\begin{array}{l}\text { Programa de educa- } \\
\text { ción y capacitación } \\
\text { ambiental }\end{array}$ & $\begin{array}{l}\text { Ejidos, comunida- } \\
\text { des, cooperativas, } \\
\text { productores, } \\
\text { prestadores de } \\
\text { servicios tu- } \\
\text { rísticos; sector } \\
\text { educativo }\end{array}$ & $\begin{array}{c}\text { Dir. municipal de } \\
\text { Ecología y direc- } \\
\text { ción de Turismo } \\
\text { CADER, } \\
\text { CMDRS }\end{array}$ & $\begin{array}{l}\text { SEMADET, SE- } \\
\text { DER, SEDEUR }\end{array}$ & $\begin{array}{c}\text { SEMARNAT, } \\
\text { SAGARPA, } \\
\text { SEP, CONAFOR, } \\
\text { CNA }\end{array}$ & $\begin{array}{l}\text { ECOBANA, CUC } \\
\text { SUR (U. DE G.) }\end{array}$ \\
\hline $\begin{array}{c}\text { Separación y } \\
\text { manejo de residuos } \\
\text { sólidos }\end{array}$ & $\begin{array}{l}\text { Ejidos, comunida- } \\
\text { des, cooperativas, } \\
\text { productores, } \\
\text { prestadores de } \\
\text { servicios tu- } \\
\text { rísticos, sector } \\
\text { educativo }\end{array}$ & $\begin{array}{c}\text { Dir. municipal de } \\
\text { Ecología y direc- } \\
\text { ción de Turismo } \\
\text { CADER, } \\
\text { CMDRS }\end{array}$ & $\begin{array}{l}\text { SEMADET, SE- } \\
\text { DER, SEDEUR. }\end{array}$ & $\begin{array}{l}\text { SEMARNAT, } \\
\text { SAGARPA }\end{array}$ & $\begin{array}{l}\text { ECOBANA, U. } \\
\text { DE G., APRO- } \\
\text { SANIDAD } \\
\text { MELAQUE }\end{array}$ \\
\hline $\begin{array}{l}\text { Promoción y diver- } \\
\text { sificación de la } \\
\text { actividad } \\
\text { turística }\end{array}$ & $\begin{array}{l}\text { Ejidos, comunida- } \\
\text { des, cooperativas, } \\
\text { productores, } \\
\text { prestadores de } \\
\text { servicios turís- } \\
\text { ticos }\end{array}$ & $\begin{array}{l}\text { Dir. municipal } \\
\text { de Ecología y } \\
\text { dirección de } \\
\text { Turismo. } \\
\text { CMDRS }\end{array}$ & $\begin{array}{l}\text { SEMADET SE- } \\
\text { DER, SEDEUR, } \\
\text { SETUJAL }\end{array}$ & $\begin{array}{l}\text { SEMARNAT, } \\
\text { SAGARPA, } \\
\text { SECTUR }\end{array}$ & $\begin{array}{l}\text { ECOBANA, Y } \\
\text { Universidad de } \\
\text { Guadalajara } \\
\text { (U. DE G.) }\end{array}$ \\
\hline
\end{tabular}




\begin{tabular}{|c|c|c|c|c|c|}
\hline \multirow[b]{2}{*}{$\begin{array}{l}\text { PROYECTO } \\
\text { ESTRATEGICO }\end{array}$} & \multirow[b]{2}{*}{$\begin{array}{l}\text { COMUNIDAD/ } \\
\text { LOCALIDAD }\end{array}$} & \multicolumn{3}{|c|}{ INVOLUCRADOS DEL SECTOR } & \multirow[b]{2}{*}{$\begin{array}{c}\text { SECTOR SOCIAL } \\
\text { O PRIVADO }\end{array}$} \\
\hline & & $\begin{array}{c}\text { DEPENDENCIAS } \\
\text { MUNICIPALES O } \\
\text { REGIONALES }\end{array}$ & $\begin{array}{c}\text { DEPENDEN- } \\
\text { CIAS ESTAT } \\
\text { ALES }\end{array}$ & $\begin{array}{l}\text { SECRETARIAS } \\
\text { FEDERALES }\end{array}$ & \\
\hline $\begin{array}{l}\text { Promover el manejo } \\
\text { sostenible de la } \\
\text { agricultura y la } \\
\text { ganadería }\end{array}$ & $\begin{array}{c}\text { Ejidos, comunida- } \\
\text { des, cooperativas, } \\
\text { productores }\end{array}$ & $\begin{array}{l}\text { Dirección de Tu- } \\
\text { rismo, CMDRS }\end{array}$ & $\begin{array}{l}\text { SEMADET, } \\
\text { SEDER }\end{array}$ & $\begin{array}{l}\text { SEMARNAT, } \\
\text { SAGARPA }\end{array}$ & $\begin{array}{c}\text { ECOBANA, (U. } \\
\text { DE G.) }\end{array}$ \\
\hline $\begin{array}{l}\text { Sensibilización } \\
\text { sobre los temas de } \\
\text { aprovechamiento } \\
\text { de agua de lluvia }\end{array}$ & $\begin{array}{c}\text { Ejidos, comunida- } \\
\text { des, cooperativas, } \\
\text { productores }\end{array}$ & $\begin{array}{l}\text { Dir. municipal } \\
\text { de Ecología y } \\
\text { dirección de } \\
\text { Turismo. } \\
\text { CMDRS }\end{array}$ & $\begin{array}{l}\text { SEMADET, } \\
\text { SEDER }\end{array}$ & $\begin{array}{l}\text { SEMARNAT, } \\
\text { SAGARPA }\end{array}$ & $\begin{array}{c}\text { ECOBANA, (U. } \\
\text { DE G.) }\end{array}$ \\
\hline $\begin{array}{l}\text { Autoconsumo } \\
\text { comunitario }\end{array}$ & $\begin{array}{c}\text { Agente municipal, } \\
\text { Familias }\end{array}$ & $\begin{array}{l}\text { Ayuntamiento, } \\
\text { CMDRS, } \\
\text { D.I.F. Municipal }\end{array}$ & SEDER & SEDESOL & U. DE G. \\
\hline Tecnología & $\begin{array}{l}\text { Localidades, } \\
\text { familias }\end{array}$ & $\begin{array}{l}\text { Ayuntamiento } \\
\text { (Dirección de } \\
\text { Promoción Eco- } \\
\text { nómica) }\end{array}$ & $\begin{array}{c}\text { SEDER, FIRCO- } \\
\text { JAL }\end{array}$ & $\begin{array}{l}\text { INIFAP, SA- } \\
\text { GARPA }\end{array}$ & U. DE G. \\
\hline
\end{tabular}

Fuente: Elaboración propia con base en el Programa de Ordenamiento Ecológico Municipal (2012-2015). * CMDRS: Consejo Mexicano para el Desarrollo Rural Sustentable; SEMADET: Secretaría de Medio Ambiente y Desarrollo Territorial de Jalisco; CEA: Comisión Estatal del Agua; FIRCO: Fideicomiso de Riesgo Compartido; DIF: Desarrollo Integral de la Familia; SAGARPA: Secretaría de Agricultura, Ganadería, Desarrollo Rural, Pesca y Alimentación; SCT: Secretaría de Comunicaciones y Transportes; SEDESOL: Secretaría de Desarrollo Social; CONAFOR: Comisión Nacional Forestal.

Los actores clave identificados en este trabajo y que participan o están involucrados en proyectos estratégicos con implicaciones en la administración local están contenidos en el Cuadro 2. La importancia de estos proyectos viene dada por la vinculación de los distintos órganos de gobierno y de la participación ciudadana. Ya que dichas acciones respecto a la gestión del medio ambiente generalmente involucran actores clave en todos los niveles de la administración pública.

Como puede observarse del Cuadro 2, los actores y factores que intervienen en la gestión sostenible para una región son diversos y pertenecientes a diferentes esferas o ámbitos de la administración pública que involucra a los distintos niveles de gobierno (federal, estatal, municipal) y la sociedad civil. Una interrupción o distorsión en la comunicación entre ellos, provoca atrasos y en ocasiones pérdida de recursos económicos y humanos de importancia para la adecuada gestión ambiental, de ahí la importancia de contar con una sociedad civil organizada.

Los actores involucrados en los diversos proyectos estratégicos para la gestión ambiental municipal del Cuadro 2 giran en torno a la lógica del modelo PER y FPEIR. Es decir, mediante estos indicadores 
se pueden representar las relaciones entre las presiones que ejercen las actividades antropogénicas sobre el medio y sus transformaciones/alteraciones que provocan en los distintos ecosistemas, y cuáles son las respuestas de política pública en materia de gestión ambiental.

Tras conocer los actores clave, se procede a señalar los problemas relevantes materia ambiental y sus posibles causas. Se encontró que los principales problemas tienen que ver con el inadecuado manejo de residuos, deficiencias en la aplicación de la legislación ambiental vigente y una escasa o nula importancia para la mayoría de los actores respecto al impacto ambiental, algo particularmente grave en el caso de las autoridades.

\begin{tabular}{|c|c|c|}
\hline Problema & Causa (s) (Presión) & Estado \\
\hline $\begin{array}{l}\text { Inadecuado manejo } \\
\text { de residuos }\end{array}$ & $\begin{array}{l}\text { Inadecuada selección y operación de los sitios donde son dispuestos final- } \\
\text { mente los residuos. (filtración de lixiviados cerca de ríos o arroyos). } \\
\text { Incumplimiento de la normativa en materia de gestión integral de residuos. } \\
\text { Infraestructura deficiente para el manejo adecuado de los residuos. }\end{array}$ & Alta \\
\hline $\begin{array}{l}\text { Presencia de impac- } \\
\text { tos ambientales }\end{array}$ & $\begin{array}{l}\text { Deficiente aplicación de las leyes sobre gestión ambiental y escaso segui- } \\
\text { miento y evaluación del impacto ambiental. } \\
\text { Escasa o nula capacitación sobre la importancia de la evaluación del impacto } \\
\text { ambiental (principalmente entre los tomadores de decisión en la adminis- } \\
\text { tración pública). }\end{array}$ & Alta \\
\hline $\begin{array}{l}\text { Degradación de } \\
\text { los ecosistemas y } \\
\text { biodiversidad }\end{array}$ & $\begin{array}{l}\text { Cambio en los usos de suelo (para usos agrícola y urbano). } \\
\text { Incendios (quemas para ganadería) y plagas forestales. } \\
\text { Tala ilegal (para construcción de vivienda, muebles o cercos). } \\
\text { Pérdida de los ecosistemas y la biodiversidad por desastres naturales (aso- } \\
\text { ciado con desmontes). } \\
\text { Aprovechamiento depredador de los recursos (pesca, caza, perforación para } \\
\text { extracción de agua). }\end{array}$ & Media-Alta \\
\hline $\begin{array}{l}\text { Vulnerabilidad ante } \\
\text { el cambio climático }\end{array}$ & $\begin{array}{l}\text { Poca concientización social sobre sus impactos negativos en el inadecuado } \\
\text { aprovechamiento de los recursos (desperdicio de agua corriente/potable, la } \\
\text { no separación de los residuos sólidos, el cuidado de la fauna, entre otros. } \\
\text { Uso excesivo de productos químicos en la agricultura. }\end{array}$ & Media \\
\hline $\begin{array}{l}\text { Contaminación del } \\
\text { aire }\end{array}$ & $\begin{array}{l}\text { Altas emisiones de gases contaminantes. } \\
\text { (El problema es estacional, ya que aumentan durante temporadas vacacio- } \\
\text { nales con un mayor aforo de parque vehicular). } \\
\text { Uso de productos químicos contaminantes por parte de los sectores (aero- } \\
\text { sol como pinturas y químicos para aseo o reparación automotriz). }\end{array}$ & Baja \\
\hline
\end{tabular}

Fuente: Elaboración propia. 
Estos problemas en el municipio, aunque no son todos, son los más representativos para los agentes clave a los que se tuvo acceso por medio de los talleres y entrevistas realizadas. Conocidos los principales problemas ambientales ahora se presentan los indicadores PER a nivel municipal que permiten entender el estado en el cual se encuentra el desarrollo sostenible.

Cuadro 4. Matriz PER en Cihuatlán de acuerdo con sectores productivos

\begin{tabular}{|c|c|c|c|c|c|c|c|}
\hline \multirow{2}{*}{$\begin{array}{c}\text { FACTORES } \\
\text { AMBIENTALES }\end{array}$} & \multicolumn{3}{|c|}{ PRESION } & \multirow[t]{2}{*}{ ESTADO } & \multicolumn{3}{|c|}{ RESPUESTA } \\
\hline & Agropecuario & Forestal & Turismo & & Agropecuario & Forestal & Turismo \\
\hline $\begin{array}{c}\text { Depuración de } \\
\text { aguas residuales }\end{array}$ & & & & ALTA & & & $x$ \\
\hline Procesos erosivos & $x$ & & & ALTA & $x$ & & \\
\hline Superficie forestal & $\mathrm{x}$ & $x$ & $x$ & ALTA & $x$ & & \\
\hline Paisaje & $x$ & $x$ & $x$ & ALTA & & & \\
\hline $\begin{array}{c}\text { Espacios de interés } \\
\text { natural }\end{array}$ & $x$ & & $\mathrm{x}$ & ALTA & & & $x$ \\
\hline $\begin{array}{c}\text { Alteración de la } \\
\text { dinámica de cauces }\end{array}$ & $\mathrm{x}$ & $x$ & $\mathrm{X}$ & ALTA & & $\mathrm{x}$ & \\
\hline $\begin{array}{c}\text { Degradación del } \\
\text { suelo }\end{array}$ & $\mathrm{X}$ & & & MEDIA & $\mathrm{x}$ & & \\
\hline $\begin{array}{c}\text { Contaminación del } \\
\text { subsuelo }\end{array}$ & $x$ & $x$ & & MEDIA & $\mathrm{x}$ & & \\
\hline $\begin{array}{l}\text { Disponibilidad } \\
\text { hídrica }\end{array}$ & $x$ & $\mathrm{x}$ & $\mathrm{X}$ & MEDIA & & $x$ & \\
\hline $\begin{array}{l}\text { Calidad de aguas } \\
\text { continentales }\end{array}$ & $x$ & $\mathrm{x}$ & $\mathrm{X}$ & MEDIA & & & \\
\hline $\begin{array}{l}\text { Diversidad bioló- } \\
\text { gica }\end{array}$ & $\mathrm{x}$ & $x$ & $x$ & MEDIA & & & $x$ \\
\hline $\begin{array}{l}\text { Generación de } \\
\text { residuos }\end{array}$ & $x$ & $\mathrm{x}$ & $\mathrm{x}$ & MEDIA & & & \\
\hline $\begin{array}{l}\text { Calidad del medio } \\
\text { ambiente urbano }\end{array}$ & & $\mathrm{x}$ & $\mathrm{x}$ & MEDIA & & & $x$ \\
\hline Calidad del aire & $\mathrm{x}$ & & & BAJA & & $\mathrm{x}$ & \\
\hline $\begin{array}{c}\text { Contaminación } \\
\text { acústica }\end{array}$ & & $x$ & $\mathrm{x}$ & BAJA & & & \\
\hline
\end{tabular}

Fuente: Elaboración propia. 
El Cuadro 4 muestra la variedad de factores ambientales que deben ser tomados en cuenta para la óptima gestión del ambiente en la región mediante la aplicación de políticas públicas ad hoc. Se ha agrupado de mayor a menor el estado en el cual los actores consideran se encuentra la degradación de las condiciones ambientales. En materia de depuración de aguas residuales no se identificaron sectores que presionan, pero el turístico ya ha comenzado a tomar acciones para no ver deteriorada su existencia. En lo que refiere a bosques, paisaje y áreas naturales en general, las presiones se tienen por parte de los tres sectores y es notorio que en los tres problemas el sector forestal no ha tomado acción alguna, peor aún, en el caso del paisaje circundante los actores revelaron que ningún sector ha tenido respuesta. Por otro lado, en lo que refiere a la alteración de la dinámica de cauces se identifica que todos los sectores han presionado, pero solamente el forestal ha tenido alguna respuesta.

Solamente dos problemas se considera tienen un grado bajo de deterioro, se trata de la calidad del aire y la calidad acústica, Para el primero se identifica al sector agropecuario como presión y como respuesta al forestal. En el caso del segundo, las presiones se identificaron por parte del forestal y turístico y sin respuesta por parte de todos los sectores. A partir de lo investigado, se encontró que uno de los principales problemas que enfrenta la gestión ambiental es la falta de voluntad política de los tomadores de decisiones en las agencias públicas. Para los distintos agentes, las autoridades solamente desean cobrar impuestos para gastarlos en campañas políticas o bien para enriquecimiento personal, no desean contribuir realmente al desarrollo económico sostenible. Este nivel de desconfianza en las autoridades lleva a dudar que los problemas identificados sean solucionados, ya que quien debería organizar los esfuerzos carece de credibilidad.

\subsection{Modelos PER y FPEIR: Sectores forestal, agropecuario y turístico}

Uno de los temas de importancia en la gestión del ambiente debido a los beneficios/servicios que genera son los recursos forestales. Aunque también son los más vulnerables, particularmente por los cambios en el uso del suelo, que conduce a la tala indiscriminada, lo que afecta la capacidad de regulación de microclimas y del ambiente en general. En Cihuatlán las actividades forestales se han caracterizado por ser depredadoras. Por lo que son necesarios proyectos de desarrollo sostenible para actividad, lo que inicia por la creación de un sistema adecuado de indicadores. 


\begin{tabular}{|c|c|c|}
\hline & PER & Indicador \\
\hline \multirow{12}{*}{ Sector Forestal } & \multirow{4}{*}{ Presión } & Pérdida de superficie forestal por deforestación \\
\hline & & Intensidad del aprovechamiento forestal \\
\hline & & Cambio en la superficie de los bosques \\
\hline & & Presencia de incendios \\
\hline & \multirow{2}{*}{ Estado } & Tasa de deforestación \\
\hline & & Cambio de uso de suelo (áreas forestales) \\
\hline & \multirow{6}{*}{ Respuesta } & Estadística de la sobrevivencia de las reforestaciones \\
\hline & & Anuarios de la superficie forestal \\
\hline & & Capacitación de la población local en manejo forestal \\
\hline & & Acciones contra la tala clandestina \\
\hline & & Inversión en reforestación \\
\hline & & Inversión en prevención y combate de incendios \\
\hline
\end{tabular}

Fuente: Elaboración propia.

La mayoría de los problemas que afectan a la sostenibilidad forestal son derivados de las actividades antropogénicas por lo que es imperante aplicar medidas para resolverlos no sólo con una legislación sobre la actividad productiva sino con políticas que promuevan y otorguen viabilidad económica y de desarrollo social en los núcleos poblacionales quienes ven en este recurso su única fuente de ingresos, aunque están conscientes de que sea una actividad "depredadora". Por ello, la gestión ambiental se convierte en una herramienta eficaz, ya que es capaz de mostrarnos mediante indicadores el estado de la situación y permite de igual forma su seguimiento. 
Figura 4. Modelo FPEIR de la actividad forestal

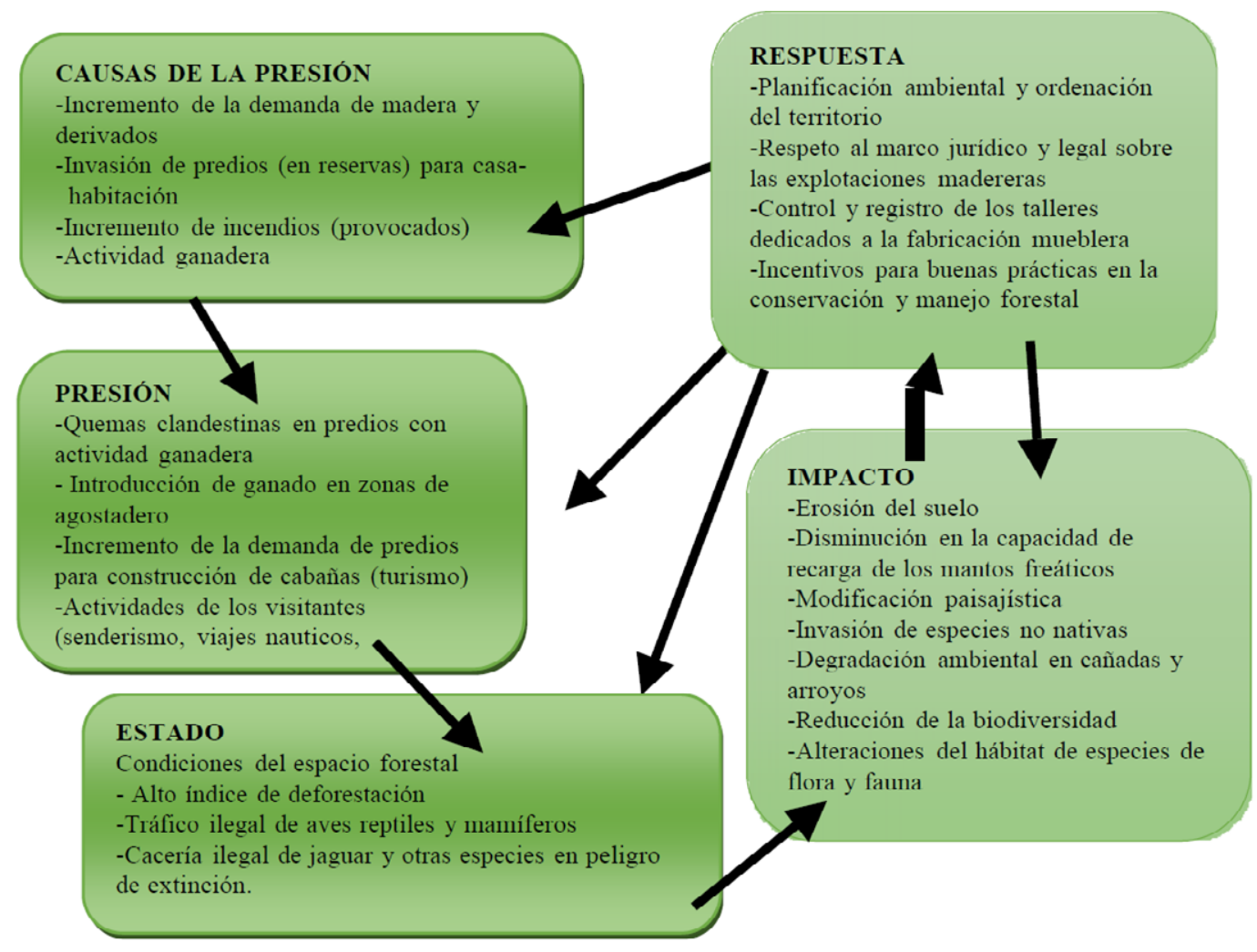

Fuente: Elaboración propia.

De acuerdo con los datos proporcionados por el proyecto México-Noruega. Para el periodo de 1993 a 2012, el estado de Jalisco (Costa Sur) registró una deforestación de 32,782 hectáreas de las cuales sólo se recuperaron (reforestaron) 1,595 por lo que la deforestación neta registrada para ese periodo fue de 31,187 hectáreas. De este total, se perdieron 29,402 hectáreas para dar paso a la creación de praderas con un uso ganadero.

Las pérdidas más representativas se dieron sobre los tipos de vegetación con asociaciones secundarias de selvas, cambiando 21,649 hectáreas a pradera y 3,172 hectáreas de tierras forestales para convertirlas en tierra agrícolas de las cuales 1,155 hectáreas correspondieron a superficies de selva caducifolia secundaria con un cambio de uso de suelo a otro de tipo agrícola. Lo anterior muestra la existencia de una elevada presión sobre las áreas forestales. Problemas de tala indiscriminada, nulo manejo forestal, invasión de predios forestales para actividades ganaderas y agrícolas, entre otros. Por lo que se debe actuar en forma adecuada en este sector para revertir estas inercias productivas que atentan contra la biodiversidad y el equilibrio de los ecosistemas. 


\section{Cuadro 6. Indicadores PER para el sector agropecuario}

\begin{tabular}{|c|c|c|}
\hline & PER & Indicador \\
\hline \multirow{10}{*}{ Agropecuario } & \multirow{3}{*}{ Presión } & Uso de fertilizantes y agroquímicos \\
\hline & & Coeficiente de agostadero (bovinos) \\
\hline & & Extensión de la frontera agropecuaria \\
\hline & \multirow{3}{*}{ Estado } & Tasa de compactación \\
\hline & & Tasa de deforestación \\
\hline & & Tasa de erosión \\
\hline & \multirow{4}{*}{ Respuesta } & $\begin{array}{l}\text { Financiamiento para el desarrollo del campo (rotación de cul- } \\
\text { tivos y mejora genética: sementales y reemplazos) }\end{array}$ \\
\hline & & Seguros de cobertura agrícola \\
\hline & & Inversión en capacitación \\
\hline & & Inversión en cambio de tecnología agrícola \\
\hline
\end{tabular}

Fuente: Elaboración propia

Debido a la actividad agropecuaria, existe un continuo avance en la degradación de suelos con alto riesgo para el desempeño medioambiental en el municipio. Especialmente, desertificación, aunado a los problemas de deforestación y las prácticas tradicionales de producción agrícola. En la región bajo estudio se práctica la ganadería de doble propósito (carne y leche) por lo que la degradación de suelos es una constante.

El siguiente esquema muestra la necesidad de realizar medidas de tipo correctivas en la legislación para el desarrollo rural y de tipo financiero mediante incentivos que permitan actuar sobre la génesis de los problemas detectados. No realizar lo anterior, puede acarrear consecuencias graves para la mayoría de productores, quienes tendrían que optar por una reconversión productiva ante suelos con poca o nula fertilidad aunados a una salinización de los mismos y una escasez de agua. 
Figura 5. Modelo FPEIR de la actividad agropecuaria

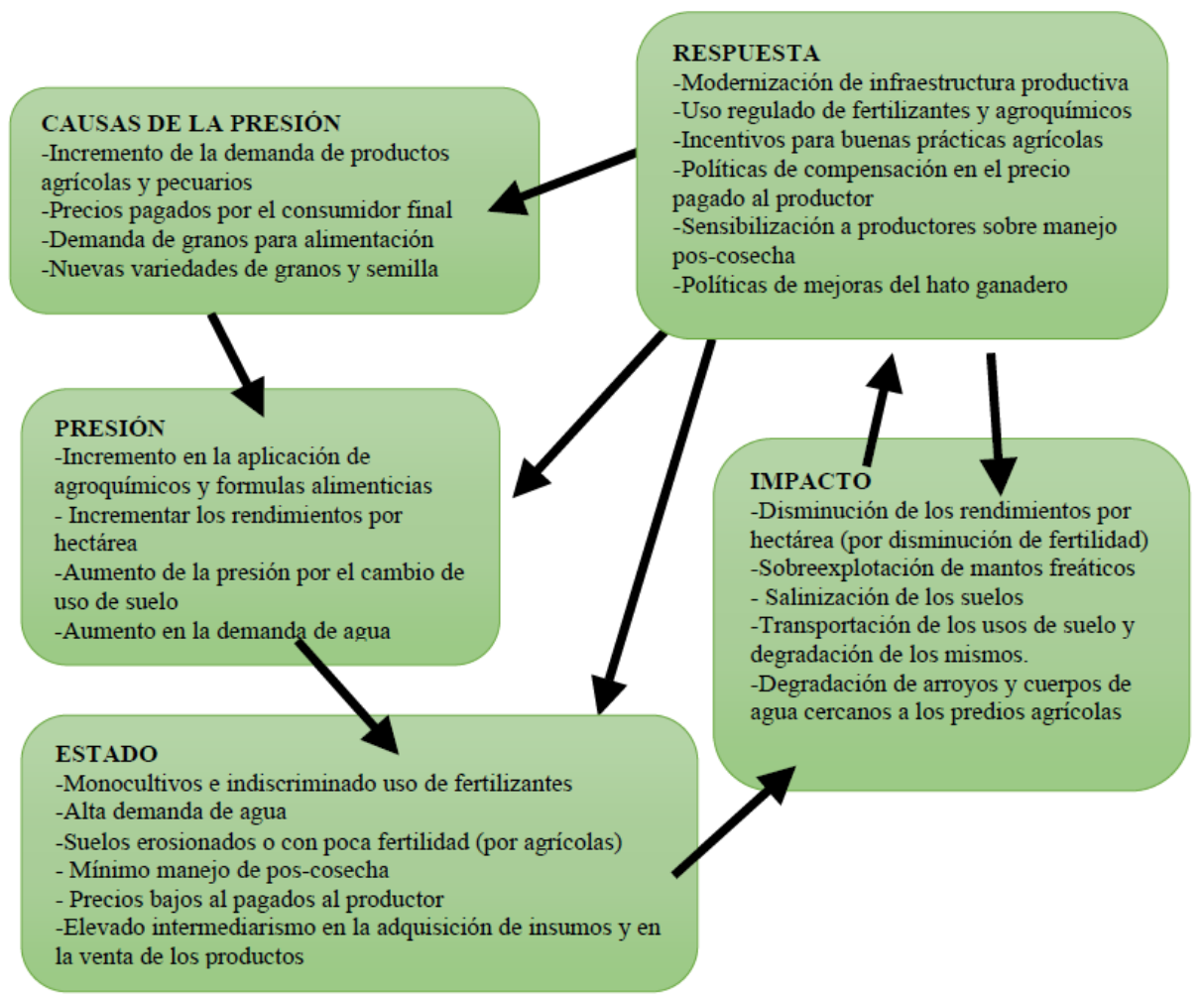

Fuente: Elaboración propia.

Siguiendo el modelo FPEIR sobre la actividad agropecuaria, aún existe en la región un limitado acceso a las nuevas técnicas de producción y estrategias de mercadeo que coadyuven a la mejora de la productividad sin necesidad de aumentar las áreas de pastoreo o de producción agrícola. Por otra parte, se encontró que se ha venido haciendo un uso indiscriminado del agua, sobre todo en los ingenios donde se realiza el procesado de la caña de azúcar. De igual forma, se tiene un problema con la aplicación de agroquímicos, los cuales se comercializan con escasa o nula regulación. 


\section{Cuadro 7. Indicadores PER para el sector turístico}

\begin{tabular}{|c|c|c|}
\hline & PER & Indicador \\
\hline \multirow{18}{*}{ Turismo } & \multirow{7}{*}{ Presión } & $\begin{array}{c}\text { Número de visitantes (mayor a la norma permitida en algunos ecosistemas } \\
\text { sensibles) }\end{array}$ \\
\hline & & Número de transportes marítimos (pesca deportiva y ocio) \\
\hline & & $\begin{array}{l}\text { Extensión de la frontera turística hacia tierras de tipo agropecuario y de } \\
\text { reservas municipales }\end{array}$ \\
\hline & & Consumo de agua potable (riego y consumo) \\
\hline & & Cambios de uso del suelo \\
\hline & & Consumo de energía \\
\hline & & Generación de residuos \\
\hline & \multirow{4}{*}{ Estado } & Elevada tasa de deforestación de manglar \\
\hline & & Invasión en ecosistemas para la construcción de infraestructura hotelera \\
\hline & & Recursos hídricos (disponibilidad) \\
\hline & & $\begin{array}{l}\text { Elevado consumo de recursos (agua) para satisfacer las necesidades de la } \\
\text { actividad }\end{array}$ \\
\hline & \multirow{7}{*}{ Respuesta } & $\begin{array}{l}\text { Financiamiento para el desarrollo rutas ecológicas como senderismo y eco- } \\
\text { parques }\end{array}$ \\
\hline & & Planeación urbanística y ordenación territorial \\
\hline & & Atención a indicadores que expresen impactos a mediano y largo plazo \\
\hline & & Incremento del bienestar social \\
\hline & & Educación ambiental para todos (visitantes y locales) \\
\hline & & Inversión en capacitación turística a los proveedores de servicios \\
\hline & & $\begin{array}{c}\text { Coinversión en el tratamiento de aguas residuales con el ramo hotelero } \\
\text { principalmente }\end{array}$ \\
\hline
\end{tabular}

Fuente: Elaboración propia.

Para el caso de la actividad turística, debido a la dependencia implícita y explícita que tiene en relación con el ambiente y los diversos ecosistemas, presenta problemas sociales más que de tipo económico, lo que compromete la imagen que suele presentar la actividad turística como industria "sin chimeneas". Por lo que un desarrollo turístico gestionado de manera sostenible es un objetivo que requiere esfuerzo por 
parte de los gobiernos locales. Esfuerzo que puede ser realizado mediante instrumentos de planeación y legislación dentro de un marco de gestión ambiental local.

\section{Figura 6. Modelo FPEIR de la actividad turística}

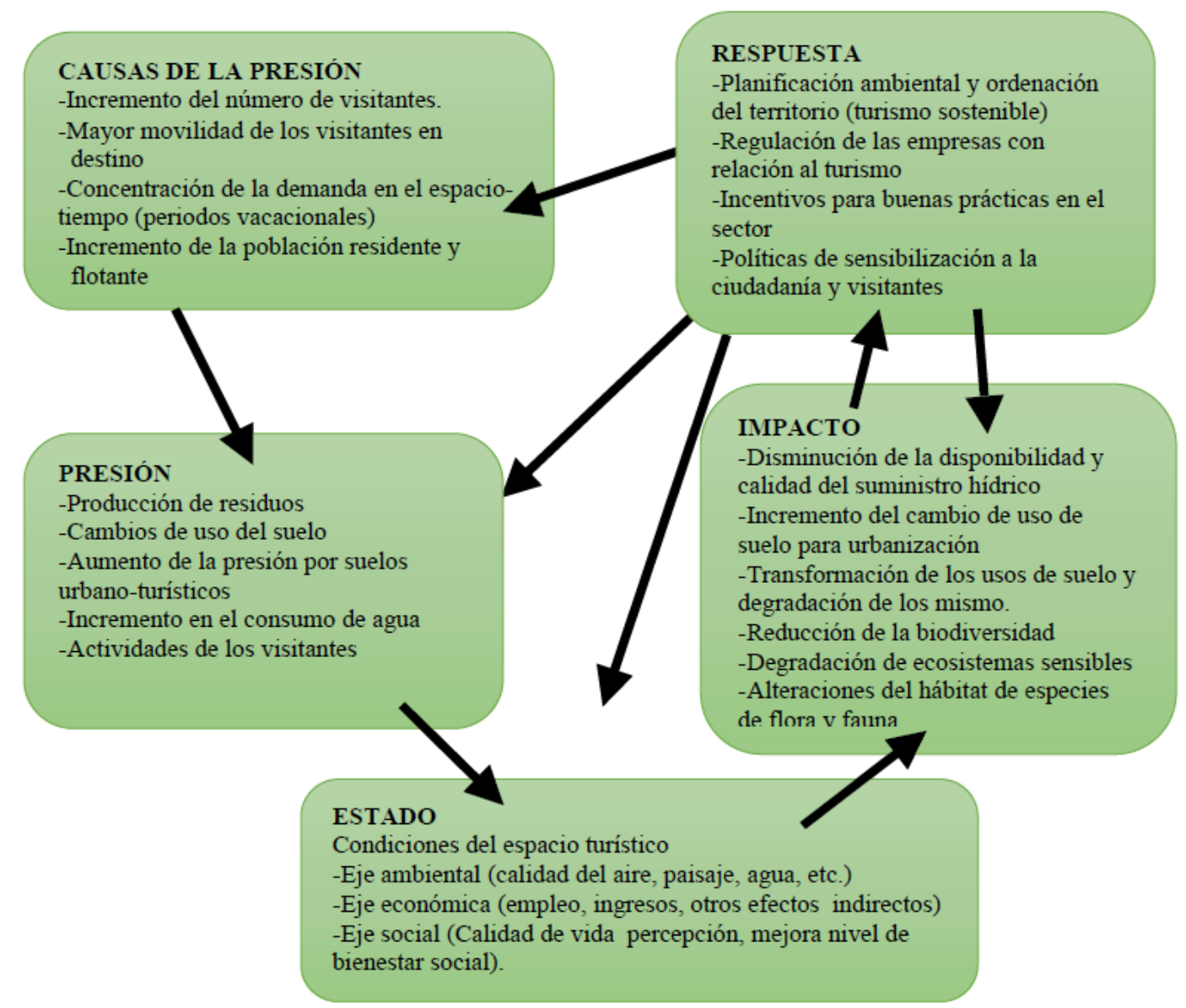

Fuente: Elaboración propia.

Los indicadores descritos en la Figura 6, si bien no son los únicos son los más comunes en la percepción tanto de la población local como de los visitantes (turistas). Por ello, es importante tener en cuenta que varias de las causas de la presión y la presión misma como tal, deriva de prácticas incorrectas de los desarrollos turísticos o actividades de ocio. Pareciera que esta actividad es totalmente incompatible con una adecuada gestión ambiental, pero realmente no es así, ya que dicha actividad puede ser sostenible. Todo depende de una adecuada educación ambiental que se traduzca en acciones concretas y entendibles para cualquier actor que faciliten una mejor acogida de las iniciativas de planificación del desarrollo municipal.

La formulación de instrumentos de gestión pública y planeación que atiendan el turismo -en sus diferentes modalidades- requiere de una amplia participación de diversos niveles en la administración pública y de otros sectores de la sociedad con el objetivo central de generar sinergias que permitan la identificación de prioridades para así formular estrategias en la implementación de acciones que aseguren la conservación de los ecosistemas, y a la vez el desarrollo del turismo en la región. 
Fortalecer la vocación turística en el municipio de Cihuatlán requiere de la incorporación de principios del desarrollo sostenible a las políticas de gestión turística, reclamando una renovación en la visión holística de la región. Visiones unidimensionales del desarrollo resultan inconcebibles, pues la propia dinámica de la actividad turística requiere de seguimientos específicos para la mejora continua de la actividad con afectación mínima de los ecosistemas.

El marco político-administrativo para la región Costa Sur y el municipio de Cihuatlán supone un claro inconveniente para la identificación y manejo de los proceso económicos, sociales y medio ambientales que debe ser superado, ya que las prioridades de gestión ambiental sustentable son superiores. Debido a lo anterior, la enorme cantidad de información que aporta el medio físico obliga a sintetizar la información para llegar a una comprensión del espacio territorial donde se actuará. Es decir, elaborar unidades territoriales que ayuden a simplificar la lectura e interpretación del territorio.

Para tal propósito existen dos grupos de unidades territoriales: 1) unidades ambientales: son creadas mediante la superposición de los diversos factores inventariados: relieve, áreas de vegetación, usos de suelo, entre otros; y 2) unidades de síntesis: estás son definidas a partir de la existencia de algún factor o aspecto primordial que condiciona la vocación del área (por ejemplo, agricultura, turismo). Es decir, se trata de verdaderas unidades de trabajo ya sea por vocación productiva como se mencionaba en líneas anteriores o por la existencia de un problema ambiental de relevancia que se esté presentando (deforestación, erosión del suelo) (ver Ivars, 2001).

Cabe señalar que el desarrollo de indicadores ambientales -además de otras herramientas de evaluación- es un proceso continuo que debe ser adaptado según las necesidades de cada iniciativa de gestión. Pues es fácil prever que su alcance e importancia será cada vez mayor en una sociedad participativa que requiere y exige información objetiva y confiable para que los agentes clave locales y tomadores de decisiones formulen sus estrategias y objetivos. Se espera que los aspectos identificados mediante la metodología PER y FPEIR sean de utilidad en los esfuerzos por elaborar indicadores que sirvan de guía para la integración y sistematización de información de tipo ambiental y productivo que coadyuven en la definición de los ejes y estrategias municipales (sin olvidar cultivar procesos de seguimiento y evaluación permanente) (Semarnat, 2006).

Además de lo expuesto, resulta importante observar las debilidades y fortalezas más destacadas, así como aquellos temas que aportan dificultades para la sostenibilidad. Por lo que es útil identificar los problemas ambientales, para después construir y/o perfeccionar los indicadores de sostenibilidad en función de la finalidad de los objetivos planteados. También es relevante analizar su contribución a la mejora del medio ambiente municipal, calidad de vida y grado de satisfacción de la ciudadanía. El análisis y diagnóstico debe ser en todos los casos previo a la aplicación de los indicadores más significativos para las problemáticas predominantes. Esto no excluye ir ampliando con el tiempo los indicadores a utilizar. Estas medidas deben estar consideradas en la planificación si se quiere transitar hacia una senda del desarrollo sostenible (González y de Lázaro y Torres, 2005). 


\section{Conclusiones}

Al visitar Cihuatlán por primera vez se tuvo la impresión de que era un municipio pequeño en el que es posible lograr un desarrollo sostenible que sirva de ejemplo a otros en el estado de Jalisco, México. Por lo que el primer paso consistía en averiguar cuál era su condición en la materia. Tras revisar la literatura especializada se descubrió la metodología PER y FPEIR, la que es apropiada para la tarea propuesta; no obstante, se enfrentaba una restricción importante: ausencia de información estadística y la propuesta de indicadores a considerar por sector.

Por lo que la investigación consistió en analizar el desarrollo sostenible, sobre la base de construir una propuesta de indicadores para tres sectores relevantes, tras conocer cuáles se consideran los principales problemas ambientales. Además, en la investigación se identificaron actores clave y pudo entrevistarse a tres de ellos y a otros conocer su opinión gracias a que se participó en tres talleres organizados por las autoridades locales y estatales.

El resultado final fue una propuesta de indicadores que se espera las autoridades municipales decidan considerar para monitorear las presiones, el estado y las respuestas a nivel de tres sectores con una activa participación en la economía local: forestal, agropecuario y turístico. La propuesta es que la medición y cuantificación se base en los resultados aquí publicados.

Se debe persuadir a los actores políticos y del sector productivo sobre los beneficios que proporciona un manejo integral del ecosistema. Por lo que contar con instrumentos de medición enmarcados en una visión compartida para las decisiones de los actores locales es una necesidad imperante, donde exista una definición de los roles y compromisos de trabajo en líneas de acción específicas, de acuerdo con sus vocaciones productivas y al estado que guardan los recursos naturales existentes en el territorio.

Los problemas ambientales con una valoración subjetiva alta fueron: inadecuada selección y operación de los sitios donde son dispuestos los residuos, así como infraestructura deficiente para el manejo de residuos. También se identificaron deficiencias en la aplicación de las leyes de gestión ambiental y escaso seguimiento y evaluación del impacto ambiental. De forma preocupante se encontró que existe escasa o nula capacitación sobre la importancia de la evaluación del impacto ambiental entre los tomadores de decisiones en la administración pública. Como problema medio alto se identificó la degradación de los ecosistemas y la biodiversidad, mientras que la vulnerabilidad ante el cambio climático se consideró de gravedad o estado medio, al final la contaminación del aire se clasificó como un problema de menor riesgo.

Adicional a lo anterior, al considerar a los tres sectores y aplicar la metodología PER y FPEIR con un enfoque cualitativo, se halló que seis problemas ambientales se pueden clasificar con un estado alto de impacto negativo: 1) depuración de aguas residuales, 2) procesos erosivos, 3) superficie forestal, 4) paisaje, 5) espacios de interés natural y 6) alteración de la dinámica de causes. De esta forma, la investigación sugiere que algunos de los indicadores de estado que deben ser cuantificados son los siguientes: 1) tasa de deforestación, 2) cambio de uso de suelo, 3) tasa de compactación, 4) tasa de erosión, 5) recursos hídricos y 6) extensión de la invasión de ecosistemas. La creación del sistema de indicadores propuesto promovería en el municipio un auténtico desarrollo sostenible. 


\section{Referencias}

Arias, Fabio. 2006. Desarrollo sostenible y sus indicadores. Revista Sociedad y Economía, 11: 200-229.

Brundtland Gro, Mansour Ahalid, Susanna Agnelli, Saleh Al-Athel, Bernad Chidzero, Lamine Fadika, et al. 1987. Our common future: The World commission on environment and development. Oxford: Oxford University Press.

Caire, Georgina. 2007. Retos para la gestión ambiental de la cuenca Lerma-Chapala: Obstáculos institucionales para la introducción del manejo integral de cuencas. En El manejo integral de cuencas en México, compilado por Helena Cotler. Ciudad de México: Secretaría de Medio Ambiente y Recursos Naturales, 195-212. Chevalier, Serge, Robert Choiniere y Lorraine Bernier. 1992. User guide to 40 community health indicators. Ottawa: Community Health Division, Health and Welfare.

Chirino, Esteban, Juan Abad y Juan Bellot. 2008. Uso de indicadores de Presión-Estado-Respuesta en el diagnóstico de la comarca de la Marina Baixa, SE, España. Ecosistemas, 17(1): 107-114.

Eizenberg, Efrat y Yosef Jabareen. 2017. Social sustainability: A new conceptual framework. Sustainability, 9(1): 1-16. http://dx.doi.org/10.3390/su9010068

Escalera, Luciano. 2013. Los principales actores de la producción científica internacional en el estado de Jalisco: 1970-2010. Tesis de licenciatura en biblioteconomía, Ciudad de México: Escuela Nacional de Biblioteconomía y Archivonomía.

European Environment Agency. 1999. Environmental indicators: Typology and overview. Copenhague: EEA. Fraser, Evan, Andrew Dougill, Warren Mabee, Mark Reed y Patrick Mcalpine. 2006. Bottom up and top down: Analysis of participatory processes for sustainability indicator identification as a pathway to community empowerment and sustainable environmental management. Journal of Environmental Management, 78(2): 114-127. https://doi.org/10.1016/j.jenvman.2005.04.009

Gallopín, Gilberto. 1996. Environmental and sustainability Indicators and the concept of situational indicators. A systems approach. Environmental Modeling \& Assessment, 1(3): 101-117. https://doi.org/10.1007/ BF01874899

Glavic, Peter y Rebeka Lukman. 2007. Review of sustainability terms and their definitions. Journal of Cleaner Production, 15: 1875-1885. http://dx.doi.org/10.1016/j.jclepro.2006.12.006

González, María y María de Lázaro y Torres. 2005. Indicadores básicos para la planificación de la sostenibilidad urbana local. Revista Bibliográfica de Geografía y Ciencias Sociales, 10(586): s.p.

Guttman, Edith, Carlos Zorro, Adriana Cuervo y Juan Ramírez. 2004. Diseño de un sistema de indicadores socio ambientales para el distrito capital de Bogotá. Bogotá: Naciones Unidas, Santiago de Chile.

IIEG. 2016. Cihuatlán, diagnóstico del municipio. Cihuatlán: Instituto de Información Estadística y Geográfica. INEGI. 2010. Censo de población y vivienda. Ciudad de México: Instituto Nacional de Estadística y Geografía. INEGI. 2015. Encuesta intercensal. Ciudad de México: Instituto Nacional de Estadística y Geografía.

Ivars, Josep. 2001. Planificación y gestión del desarrollo turístico sostenible: propuestas para la creación de un sistema de indicadores. Alicante: Instituto Universitario de Geografía, Universidad de Alicante.

Mogheir, Yunes y Ihab Lubbad. 2008. Development of monitoring and evaluation system for wastewater issues in Palestine. International Journal of Environment and Pollution, 33(1): 54-71. http://dx.doi.org/10.1504/ IJEP.2008.018464 
Neri, Ana, Patricia Dupin y Luis Sánchez. 2016. A pressure-state-response approach to cumulative impact assessment. Journal of Cleaner Production, 126: 288-298. https://doi.org/10.1016/j.jclepro.2016.02.134

OCDE. 1993. Core set of indicators for environmental performance reviews: A synthesis report by the group on the state of the environment. Paris: Organización para la Cooperación y el Desarrollo Económico.

OCDE. 1998. Toward sustainable development: Environmental Indicators. Paris, Francia: Organización para la Cooperación y el Desarrollo Económico.

Orenstein, Daniel y Dalit Shach-Pinsley. 2017. A comparative framework for assessing sustainability initiatives at the regional scale. World Development, 98:245-256. http://dx.doi.org/10.1016/j.worlddev.2017.04.030 Ott, Wayne. 1978. Environmental indices: Theory and practice. Michigan: Ann Arbor Science.

Pannell, David y Steven Schilizzi. 1999. Sustainable agriculture: A matter of ecology, equity, economic efficiency or expedience? Journal of Sustainable Agriculture, 13(4): 57-66. http://dx.doi.org/10.1300/J064v13n04_06 PED 2030. 2007. Plan Estatal de Desarrollo Jalisco 2030. Guadalajara, México: Gobierno del Estado de Jalisco.

Pires, Alex, Jordi Morato, H. Peixoto, Verónica Botero, L. Zuluaga y Apolinar Figueroa. 2016. Sustainability assessment of indicators for integrated water resources management. Science of Total Environment, 578: 139-147. http://dx.doi.org/10.1016/j.scitotenv.2016.10.217

Quiroga, Rayén. 2007. Indicadores ambientales y de desarrollo sostenible: avances y perspectivas para América Latina y el Caribe. Santiago de Chile, Chile: Comisión Económica para América Latina y el Caribe.

Rapport, David y Anthony Friend. 1979. Towards a comprehensive framework for environmental statistics: a stress-responseapproach=Projet détablissement d'un système général d'information sur lenvironment au Canada: l'approche agression-réaction. Ottawa, Canadá: Minister of Supply and Services Canada.

SEMARNAT. 2006. Estrategia de educación ambiental para la sustentabilidad. Ciudad de México, México: Secretaría de Marina y Recursos Naturales.

Sun, Tengteng, Wenpeng Ling, Guangsheng Cheng, Pupu Guoa y Ying Zeng. 2016. Wetland ecosystem health assessment through integrating remote sensing and inventory data with an assessment model for the Hangzhou Bay, China. Science of the Total Environment, 566(1): 627-640. https://doi.org/10.1016/j. scitotenv.2016.05.028 